\title{
Conflict between Developing Economic and Protecting Environment
}

\author{
Longlong Guo \\ Beijing Representative Office in Beijing \\ Alterral Environmental Science and Technology Consultant Company (The Netherlands) \\ Room604, Unit 2, Building No. 26, Zhiqiang Yuan, Wenhuiyuan Road \\ Haidian District, Beijing, China \\ E-mail: guo@ruc.dk, harry99211@hotmail.com \\ Hongbo Ma \\ Tangshan Kailuan Oriental Power Co. Ltd \\ A-601, ShiJi HuaTing, XinHuaDao, Tangshan city, Hebei, China \\ E-mail: mahongbo777@hotmail.com
}

\begin{abstract}
The economy growth is always the attention focal point to every country. The economy growth impact the protecting environment, on the contrary the protecting environment also impacts the economy growth. Whether the environment is a factor considering the economic growth? The core answering these questions is how to regard the relationship between economic growth and environment. Concerning on the situation of economic and environment whether has the intrinsic relation or has any type relation, this still has the dispute. In this essay I will analyze the conflict between the developing economic and protecting environment. Through the analysis cause where can get a balance between them.
\end{abstract}

Keywords: Environment, Economic growth, Poverty, Conflict, Contradiction, Environmental Kuznets curve

\section{Introduction}

Environment not only provides the substance foundation and activity space for human, but also is responsible for production castoff by human activity. Economic development not only enhances the integration national power and improves the people's life quality, but brings a number of serous environmental problems, such as air pollution, water pollution, soil degradation, desertification, and so on. Whether does economic growth affect the environment? On the contrary whether also does the protecting environment affect the growth economy? Whether is protecting economy and protecting environment a pair of contradiction or not? What creates the environment problems? Poverty is a main factor. Solving this problem is that developing economy. How to increase economy under the protecting environment? Analyzing their relationship is the focal point. Problem formulation: what is the conflict between developing economic and protecting environment?

\section{The developing economic brings some environmental problems}

Economy development is obvious at present. Many multinational enterprises have been invested following the all kinds of increased industries and agricultures. These such as machine, textile, chemical plant, foodstuff, and so on, not only are the record of the economic development, but also provide a great deal of working opportunities for the labor market, and reduce the burden of the country. That's the positive points, but it has the negative points like the traffic jam, pollution, chemical, etc, a series of serious problems.

In the traffic point, "The environment impact of transport has now become a global issue. Environmental impacts from transport in the developed world are now equaled or exceeded by those in developing countries. This is alarming given the relatively low level of car ownership and use in developing countries. Equally alarming is the advanced of modes of transport that are damaging to the environment and health, while less damaging modes are retreating. The impact of transport affects the global, regional, and local environment. It is at each of these levels that action needs to be focused in order to reduce and mitigate the impact on the environment." (1) The gases like $\mathrm{CO}_{2}, \mathrm{SO}_{2}, \mathrm{NO}_{\mathrm{X}}$ from the transport directly impact the climate with rising temperature resulting the global warming. "Global warming has number of 
effects and may result in change in climate, especially rainfall patterns which increase the likelihood of more intense tropical storms and will have significant consequences for agriculture production. Rising sea levels due to thermal expansion of the ocean and melting of glaciers will pose a threat to wetlands. Pacific islands and atolls as well as large areas of the world's densely populated coastal regions. Increasing levels of risk and costs associated with accelerating coastal erosion, flooding and increases in salinity of estuaries and aquifers can be expected."(2)

Economic development, through its indirect impact on social and cultural factors, lowers fertility rates. A concern for population growth must be a part of a broader concern for a more rapid rate of economic and social development. Increasing the population, the population density in the city are getting bigger and bigger, the pollution problems from burning coal, grey water and solid waster from household also become serious. At the same time, lessen of urban virescence area lowers the environmental purification capacity leading to the more intensive pressure to the environment. On the other hand, following the increasing economy, people from countryside who invade the cities and towns with certain dimensions not only baffle the urban development, but cause a series of environmental issues, such as air pollution and lack water resource.

\section{Building capacity for environment policy}

What is capacity for environmental protection? "A society's ability to identify and solve environmental problem, generally speaking, the capacity problem is not specific to the field of environmental policy. It can be found also in other policy fields. Lack of ecological, technological or administrative knowledge, lack of material or legal resources, the weakness of environmental organizations or institutions in relation to vested interests are well-known examples of such limitations. The main implication for the debate on sustainable development is that long term strategies must include concepts for improving the conditions of environmental capacity building." (3) In a country, the centre government is the authority to make the policy, regulation and the planning. Moreover the environmental protection agency is governed. When its economic strength and science and technology still remained at a low level, active public participation in environmental protection could be more effective at a lower cost. The public participation is like individuals, student groups, social groups, and semi-governmental organization. Particularly in the recent years, various public media has been increasing, such as television, internet, environment newspaper, many major newspapers, journal and magazines. Through adsorbing public opinions, spreading the public participation and increasing the performance of the law and regulation, government can revaluate and revise the policies in order to carry out the environmental impact assessment for the all kinds of pollution enterprises. To build the capacity for environmental protection, getting some difference voice from the non-governmental proponents is the very necessary. "There are three important groups of environmental protection, all of them able to influence polluters directly:

Environmental organizations

The media

Ecological innovative firms,

They are the factors in environmental improvements within industry."(4) Government environmental protection institutions can adopt the proponents of environmental policy from the non-governmental interest organizations to build the capacity of environmental protection. Public participation has gained the significant success, but intervention limitation reduces the public participation efficiency. How to efficiency organized the public participation groups is a challenge to solve the environmental problems. At the same time, the government should not only cooperate with them, but support the finance assistance and give the power to them.

\section{Analysis the conflict between economic and environment}

The effective implementation of market mechanism's precondition is a clear property right system, if only privatizing the property right to individual, the government could manage and implement the requirements of environmental protection and run in a sustainable way. Economic rationalism is a branch of market mechanism to achieve public ends. The market is a powerful tool to change individual and institutional behavior. If success, they can achieve environmental objective at less cost and with less opposition tan traditional regulatory approaches. Economic rationalism plays out in different ways in different societies, but it focuses on the conversion of environmental resources to private property. "Markets are systems based on commodity exchange, in which goods, service, and financial instruments are exchanged for each other. Markets work smoothly to the extent that participants in transactions can be confident that they do in fact have a right to sell or buy the goods in question ---in other works, they have property right, be it to a car, a can of beans, a company, a bond, or a piece of land. If we are to have markets in environmental goods, then we need private property rights in these goods too. According to economic rationalism, specification and enforcement of these rights is the main task of government when it comes to environmental matters. People tend to care more for what they hold privately than for what they hold in common with others; this is why there is more litter in public parks than in private gardens, or why public grazing land in the American west is more degraded than the private land." (5) For example in China the present economy is located with the innovation phase. The national enterprises 
have transformed the private sector and joint-stock ones, the bigger bank also start developing the stock system, the environmental agency is beginning to innovate and catch the opportunity to form an effective and efficiency monitoring of market mechanism to control destruction and improve the environmental protection.

\subsection{Poverty creates the ecological environment degradation}

Poverty is one of the main causes of the environmental degradation. "inadequate technical know-how and managerial capabilities, common poverty resource management, and pricing and subsidy policies have been the major themes addressed and the solution suggested have been essentially techno-economics ones. Deeper socio-political changes or changes in cultural values are either ignored or paid lip-service."(6) In the figure 1 showing a more realistic representation of the poverty environmental degradation

Increasing economic is a main operational objective to solve the problem between poverty removal and protecting environment. Economic growth may occur simultaneously with either an improvement or deterioration in environmental quality. In order to analyze the deeper detail cause between developing economic and protecting environment, a relative case study from the countryside and urban in China will be provided in the following text.

\subsection{A case study from the countryside and urban in China}

On the one hand in the countryside, the poverty reclaims wasteland to cause soil erosion, herded to the sparse lawn causes the prairie degenerate; cut the tree to burn the firewood to destroy the forest resources. This perspective although makes reasonable and possibly is in reality some phenomena, but this is some superficial phenomena frequently. The soil erosion serious time, is our country implements "regards grain as the key link" the policy time. The north prairie degeneration in the very great degree is the result of the country summoned to open up wasteland and lawn to plant grain massively, in the annual rainfall insufficient 400 millimeter places, the land plowing very quickly causes the sand. But the our country forest resources two large-scale destructions was in 1958 builds up the steel and iron time greatly, another was $20^{\text {th }}$ century at the end of 70's countryside management system moments change time. Therefore, these government policies in the formulation time has not carried on the sufficient environmental risk assessment, only then has created the serious ecological environmental problem. But in fact, farmer when daily life and practical training, protects the local recourses. The farmer often plants the trees nearby the around house, regards them for to protect the village forest, the scenic forest. The activities of the farmer participating in the over-cutting forest mainly are the policy with the national forestry and the power to concern. If the forestry policy is changeable, the forestry land right of management, the usufruct are unstable, "public resource tragedy" no matter can occur in wherever.

On the other hand in the urban, cause environmental problems which the humanity pays attention, first occurs in the city. In an each one very small city space, is gathering the massive population is carrying on the massive productions and the life activity, massively discharges the pollutant is unable promptly to dissipate, the dilution, decomposes and disperses, causes the serious air pollution, the water pollution, the waste pollution and the virulent harmful dangerous material harm. The city since long ago in particular is far away impoverished. But along with urbanized advancement speeding up with the industrial structure adjustment, a city poverty crowd is forming. China condition is that the urban environmental pollution in quite is also serious, the city poverty problems already reappeared. But in policy stratification aspect, also does not have a system on the city to reduce poor arrangement. On the one hand, the city poor people more receive the environmental pollution harm. When the city drink water is polluted, the poor person does not have the money to by the mineral water; when the air pollution is serious, the poor person does not have the money to buy the air cleaner. When treatment environmental pollution, if does not have the advantageous policy arrangement, the poor person possibly bears the big share treatment expense. In a sense, the poor person more exposes during the environmental pollution, possibly more receives the virulent harmful waste harm, and thus is sick and the risk is bigger. When the poor person contracts slight illness, with the very high proportion perhaps the human choose does not go see a doctor, economizes is important consideration, because the present medical expense rate of rise is higher than the people to receive the level greatly the rate of rise, this further increased the poor person to contract the big sickness, when the risk once trouble big sickness, poor person's living standard rapidly will drop. Because sickness returns poorly, forms a poverty big reason.

\subsection{Analyzing the conflict using Environment Kuznets Curve}

The economy growth is always the attention focal point from every country. Whether can the economy growth restricted by environment? Whether can the environment improved impel the developing economy? Whether is the environment a factor when considering the economic growth? The core answering these questions is how to regard the relationship between economic growth and environment. Generally speaking one economy in the certain time with biggest productivity can be decided by the use economy resource at that time. Therefore the increased speed and potential of the economy are decided by its economical resource total quantity and development way. In the traditional economic development opinion industry growth (GDP) is regarded as only symbol, and realizing the national industrialization and industry civilization also is a symbol. In the realistic economic life this development opinion performs a goal for gross 
national production and rapidly increasing. But in the traditional opinion a country with high GNP is a country with successful economy and prosperity. Pursued GNP growth became a goal and power for national economy. From the developed country or developing country one-side pursuing GNP brings a serious outcome: the environment worsens, resource shorten, people welfare level dropped and so on. Why is like these, because this type of economy is not based on the ecology foundation. On contrary in some countries sacrificing environment replaces development. The result is the ecosystem is broken, and finally development economy can't be persisted without perfect ecosystem. In present GNP index not only natural resource and environment quality didn't be reflected, but also the resource price and environment price for economic growth didn't be stated in a country. With more pollution and more resource consumption the increasing GNP is faster. It displayed the boom economy has the very big falseness in the traditional economic development opinion. In fact understanding the relationship between economic growth and development has mistakes. The development is broader than the growth. Development not only is the output increased, but also includes environment quality improvement.

According to the Environmental Kuznets Curve (The environmental Kuznets curve is a hypothesized relationship between various indicators of environmental degradation and income per capita. In the early stages of economic growth degradation and pollution increase, but beyond some level of income per capita (which will vary for different indicators) the trend reverses, so that at high-income levels economic growth leads to environmental improvement.) Showing in figure 2 , in the early period of developing economic pollution increases and reaches a maximum level and eventually starts to decrease following the rising income.

The environmental Kuznets curve states along with the developing economy and increasing income and enhancing environment awareness the people will start a good quality environment. The enlargement of environment protection investment and environment quality makes up the early time to loss and keeps the dynamic balance of environment quality supply and demand. Finally the environment quality and economy will synchronization positive cycle with increasing capacity of investment and increasing sustainable development. For example in China near for 15 year the environment Kuznets curve matches for 15 fast economical development with the economy launching phase, industrialization and town industries. The requirement of resource is increased greatly and the pollution charge also is increased rapidly. All these indicated our country the economy development is being at the transformation stage because the coarse type of economy growth didn't changed at all. In the next period the environmental Kuznets curve must display the $\cap$ horizontal stage for quite long. Here also have a figure 3 to explain conflict between economy and environment.

From the below figure 3 showing, the economic affects pollution; on the other hand pollution also affects income. First, income directly influences the environmental quality because pollution is the environmental by product. In environmental quality increasing improvement demands always accompanies the growing income through some driving forces such as public and individual control measurement, technological progress, and structural changes in consumption, production, international trade and institutions, pollution reduced, and the relationship between income and environment would also be influenced by some exogenous variables such as traditional production factors, policies, population density and variables. Second the pollution activity on production is also multiple. (1) Pollution is the negative externality directly reducing output and productivity per capital and labor. (2) Since emission permit with greater levels may increase the availability of more human and per capital for production when enterprises reduce pollution emission, their production costs are raised and outputs are reduced.

The development economy and the protection environment, sometimes, are contradictory in particular in the short-term. But this kind of contradiction had the condition, in the majority situation, this kind of contradictory performance is, protected the environment request to reduce the development path choice space. In the reality, this kind of space nearly always exists, sometimes possibly needs us to develop. A typical example is, Sweden for protects in the 20th century 70's the environment when forbids the use leaded gas gradually, at first estimated this can increase the use gasoline cost. When, to forbid the leaded gas use completely, the new technology is created, not only can substitute the lead function, but also the new technology is cheaper. The final result is, polluted was eliminated, the cost also reduced, the mew technical choice has avoided the development and the environment contradiction. Moreover, manages the good eco-tourism, also can while obtain the economical development, protects the resources environment. The development economy and the protection environment are pair of contradictory, must get rid poverty, must endure the certain time the environmental pollution or the ecology degeneration; must protect the ecological environment, must endure poorly.

Removal poverty and protecting environment is not inevitably contradiction. In the reality they possibly exists the conflict, is always the people technology choice result, is some kind removal poverty way to cause the contradiction which perhaps some protection environment way creates, but the people may choose other ways originally to avoid the two the contradiction which will exist possibly in the near future. In the long-term view, eliminates poverty and protecting environment not only does not have the contradiction, but also nearly always mutually promotes positive cycle. When poverty is removal, people increase to the environment service demand, and people to be more positive 
improve the environment on own initiative, at the same time also may have more investments to maintain the good environment. The good environment can provide for the people more new development opportunities. Today obtains more and more many approvals in humanist new conception, the good environment should become human's development essential condition, but no longer is the luxurious demand.

Looking from the economics, the environmental problem is the economic problem. The environmental pollution is caused by the production process with external diseconomy. Namely the enterprise of pollution didn't calculate harm about the pollutant impacting the environment in production cost. Solving the problem the enterprise should put the external diseconomy in the production cost and reflected to the product price. The government department forces the enterprise to carry out this action through the law and regulation and economical tool like environment tax revenue.

\section{Conclusion}

Whether is the developing economy and protecting environment a pair of contradiction? The answer depends on the economy development stage. In the developed country the developing economy and protecting environment is not a pair of contradiction because of environment improved along with the economic structure changed. But in the developing country it is a pair of contradiction because of environment worsens with a high speed economy increasing. The choice of the industrial structure is a factor affecting the environmental pollution. Generally speaking by agricultural and light industry pollution level low; the manufacturing industry proportion high country the pollution degree can be high inevitably. Technology also is an important indicator to affect the environment. The country of using low technical can consume more resources and more pollution.

In economic development low stage the economic activity is low. In the economy launching phase the manufacture is developed greatly. The result is the resource consumption surpasses the resource generation. The environment worsens in an economical development higher stage. When economic structure changes, the pollution industry stops producing or is sifted. The environmental condition starts to improve. Along with economic development people will pay more attention to the environmental protection. The environmental protection fund also will be increased. The protecting environment meant the fund invested because a lot of environmental protection equipments are very expensive. In the long term, the disbursement and effect of protecting environment is an important factor affecting environment Kuznets curve.

\section{References}

David I. Stern: International Society for Ecological Economic, Internet Encyclopaedia of Ecological Economics, the Environment Kuznets Curve, Department of Economic, Renesselaer Polytechnic Institute, Troy, NY 12180, USA June 2003

John S. Dryzek: The Political of the Earth-Environmental Discourses-Part III Solving Environmental Problems, Oxford University Press 1996, page 105. Main course: Policies, Planning and Regulation Related to the Environment, Global, Regional and Theoretical/Methodological Considerations, section 2 lecture 1, page 29

John Whitelegg: Critical Mass, Transport, Environment and Society in the Twenty-first Century, Pluto Oress, London, 1986, page 115. Main course: Policies, Planning and Regulation Related to the Environment, Global, Regional and Theoretical/Methodological Considerations, section 2, page 41

John Whitelegg: Critical Mass, Transport, Environment and Society in the Twenty-first Century, Pluto Oress, London, 1986, page 115. Main course: Policies, Planning and Regulation Related to the Environment, Global, Regional and Theoretical/Methodological Considerations, section 2, page 41

M. Jannicke: The Political System Capacity for Environmental Policy, Berlin 1992. Main course: Policies, Planning and Regulation Related to the Environment, Global, Regional and Theoretical/Methodological Considerations, section 2 lecture 3, page 92

M. Jannicke: The Political System Capacity for Environmental Policy, Berlin 1992. Main course: Policies, Planning and Regulation Related to the Environment, Global, Regional and Theoretical/Methodological Considerations, section 2 lecture 3, page 97

Sharach Chandran M.Lele: Sustainable Development: A Critical Review, World Development, Vol.19, No. 6, pp.60621, 1991, printed in Great Britain, Energy and Resource Group, University of California, Berkeley, page 613. Main course: Policies, Planning and Regulation Related to the Environment, Global, Regional and Theoretical/Methodological Considerations, section 1 lecture 1 page 33

Sharach Chandran M.Lele: Sustainable Development: A Critical Review, World Development, Vol.19, No. 6, pp.60621, 1991, printed in Great Britain, Energy and Resource Group, University of California, Berkeley, page 614. Main course section 1 lecture 1 page 34

Van Ewijk, C and S. Van Wijnbergen, "Can Abatement Overcome the Conflict between the Environment and Economic 
Growth?" Vrije Universiteit Amsterdam, 1995

Madhusudan Bhattarai and Michael Hannig: Institutions and the Environmental Kuznets Curve for Deforestation: A Grosscountry Analysis for Latin America, Afria and Asia, Clemson University, South Carolina, USA

Policies, Planning and Regulation Related to the Environment, Global, Regional and Theoretical/Methodological Considerations, Department of Environment, Technology and Social Studies, main course lectures, Roskilde University, Denmark, 2005

Stern, D.T., M.S. Common, and E.B. Barbier: "Economic Growth and Environmental Kuznets Curve and Sustainability Development" world development. Responsible Growth for the New Millennium, Integrating Society, Ecology and the Economy, the World Bank, Washington, D.C. 1996

Jeroen C. J. M. vam den Bergh \& Jan van der Straaten: Economy and Ecosystems in Change, Analytical and Historical Approaches. Department of Spatial Economics, Free University, Amsterdam; European Centre for Nature Conservation and Department of Leisure Studies, Tilburg University, Tiburg, the Netherlands,1997

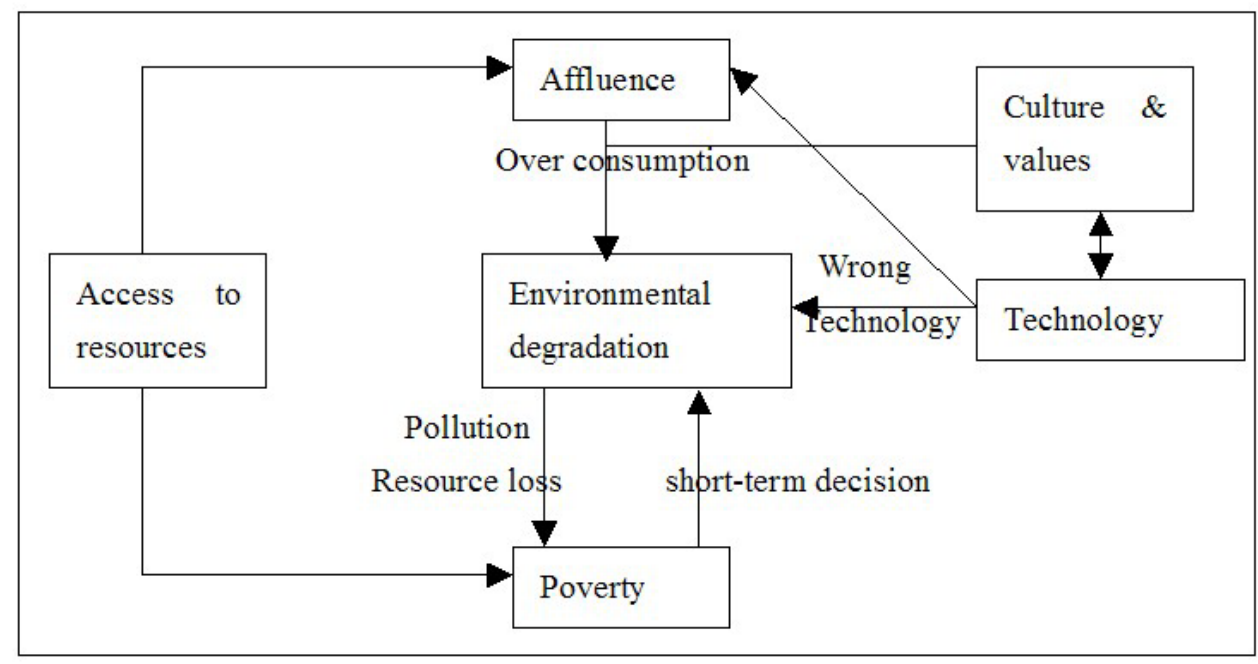

Figure 1. a realistic representation of the poverty and environmental degradation (source: Sharach Chandra M. Lele, 1991) (7)

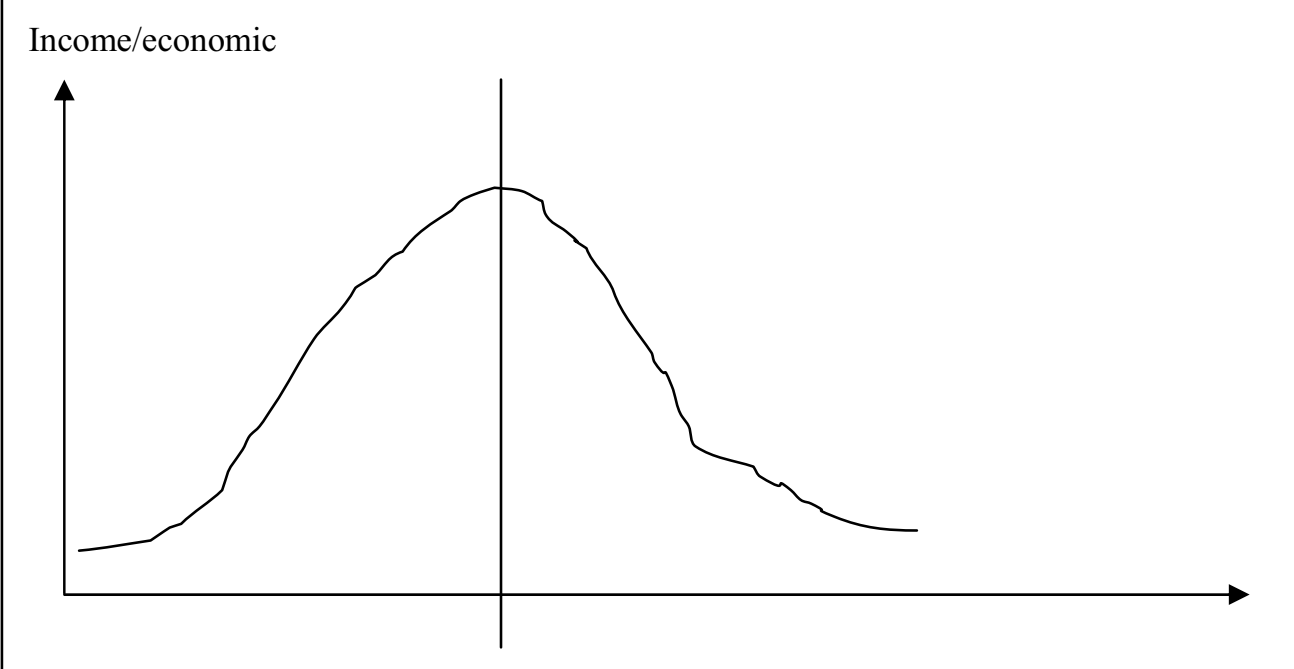

Figure 2. the Environmental Kuzents Curve (David I. Stern, June 2003) (8) 


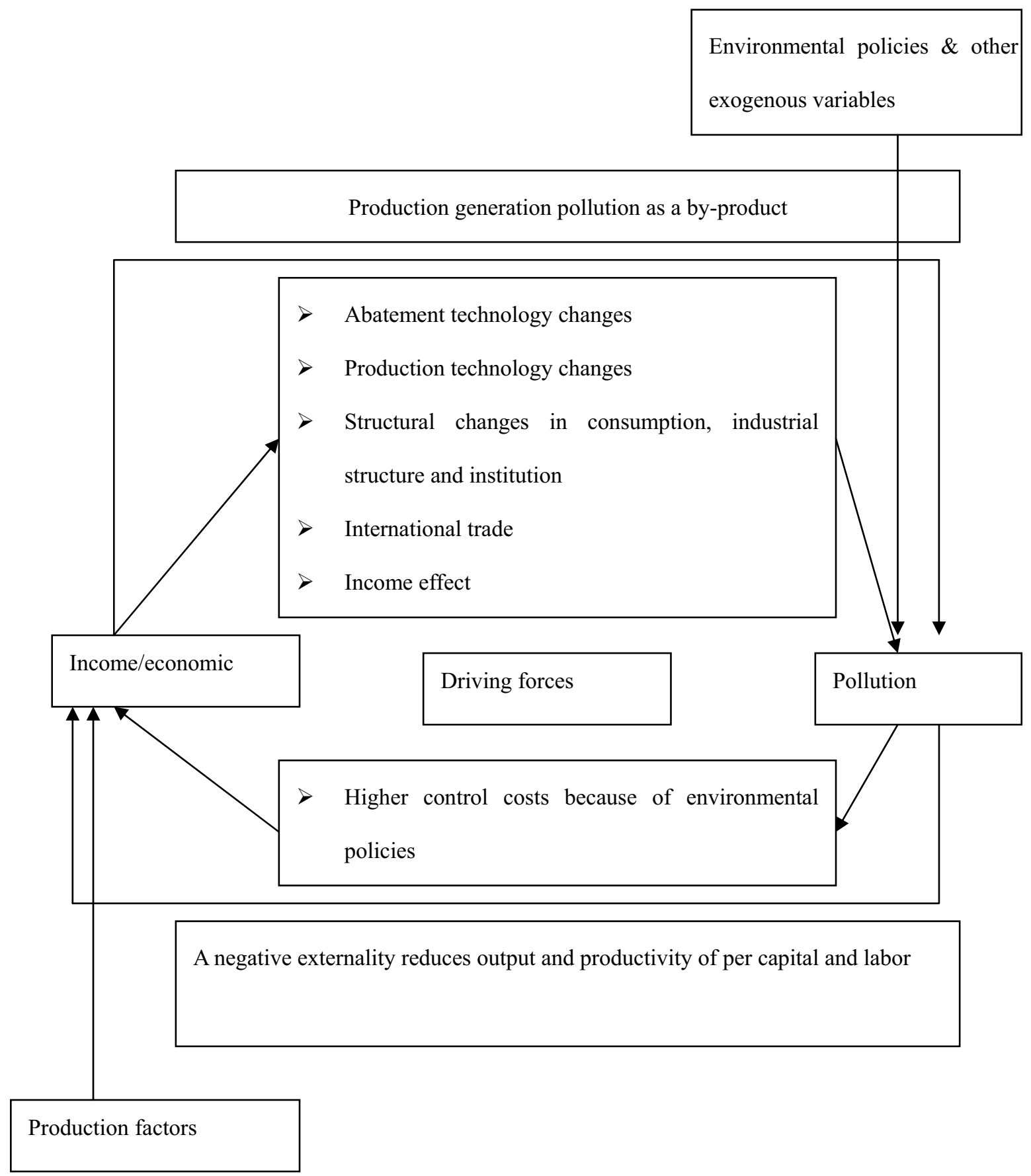

Figure 3. The relationship between income and the environment (source: Van Ewijk, C and S. Van Wijnbergen, 1995) (9) 